\title{
Study on Critical Infiltration Behavior and Law of Liquid Aluminum Alloy in Carbon Fiber Preform
}

\author{
Yuqin MA* \\ School of Mechano-Electronic Engineering, Xidian University, Taibai South Road No.2, Xi'an, Shaanxi, P.R.China, \\ 710071 \\ cross ref http://dx.doi.org/10.5755/j01.ms.26.4.22105
}

Received 20 November 2018; accepted 31 March 2019

\begin{abstract}
Infiltration effect is an important factor for the preparation of ideal $\mathrm{CF} / \mathrm{Al}$ composites by liquid infiltration method, so it is necessary to study the infiltration law of aluminum alloy in carbon fiber preform to obtain composite with sufficient and uniform infiltration effect. Through theoretical analysis and calculation of statics and dynamics, critical infiltration pressures of the liquid aluminum alloy in the $2 \mathrm{D}$ carbon fiber preform were $0.53 \mathrm{MPa}$ and $3.24 \mathrm{MPa}$, respectively, when carbon fiber volume fraction was $45 \%$. Mechanical pressure infiltration method was used to study critical infiltration pressures and behavior of the liquid aluminum alloy in the $2 \mathrm{D}$ carbon fiber preform, and the experimental results indicated that the infiltration front of aluminum alloy had never broken through the surface of carbon fiber preform, when the infiltration pressure was 3.5 MPa. Carbon fibers and aluminum alloy were separated and the infiltration effect was not ideal under the pressure of $3.5 \mathrm{MPa}$. When the infiltration pressure was $7 \mathrm{MPa}$, the infiltration could be implemented. The actual infiltration pressure of the experiments is greater than the theoretical calculation value, because viscous resistance, solidification resistance and other factors are ignored in the calculation process. However, infiltration depth increases with increase in infiltration time at infiltration pressure of $7 \mathrm{MPa}$, and this verifies the correctness of the previous theoretical research results.

Keywords: critical infiltration pressure, liquid aluminum alloy, carbon fiber preform, composite, microstructure.
\end{abstract}

\section{INTRODUCTION}

Carbon fiber reinforced aluminum matrix $(\mathrm{CF} / \mathrm{Al})$ composite is one of the research hotspots in the development of high properties structural materials, and it has light quality, high specific strength, high specific modulus and low coefficient of thermal expansion. It can be applied in the fields of aerospace, weaponry, automobile industry and so on. However, the wettability between carbon fiber and aluminum alloy is poor, and fiber volume fraction of the continuous two-dimensional (2D) carbon fiber preform is large. The fiber gaps are small and uneven, and the critical infiltration pressure is large, so it is very difficult to achieve full and uniform infiltration. This results in a complex preparation process and high cost, and it is a great challenge to prepare ideal CF/Al composites. Liquid infiltration is one of the common methods for preparing CF/Al composites. In order to obtain high property $\mathrm{CF} / \mathrm{Al}$ composites, it is necessary to ensure infiltration sufficiency and uniformity of liquid aluminum alloy in the carbon fiber preform [1]. If infiltration effect is poor, there will be large pores and no infiltration areas in the composites, and this will result in properties of composites will be poor. Therefore, it is very important to study infiltration law of alloy in carbon fiber preform to obtain CF/Al composites with sufficient and uniform infiltration effect $[2,3]$.

There were some researches on the infiltration behavior of fiber or particle reinforced metal matrix composites by domestic and foreign experts. Mortensen

\footnotetext{
${ }^{*}$ Corresponding author. Tel.: +86-29-88203115.

E-mail address: mayuqin0702@163.com (Y.Q. Ma)
}

and others [4] deduced the formula of the critical infiltration pressure of liquid metal infiltrated into fiber preform, then they discussed the temperature field of a pure metal infiltrated fiber preform from the perspective of heat transfer theory and experiment. Kaptay and others [5] put forward new ideas on the basis of Mortensen's calculation formula and they had studied the effect of fiber arrangement on infiltration. According to the basic principle of fluid mechanics, Yu and others [6] established the mathematical model for the preparation of metal matrix composites. Then they used this model to analyze the infiltration process of $\mathrm{ZA} 22 / \mathrm{Al}_{2} \mathrm{O}_{3}$ composite and to guide the preparation of this composite with excellent properties. In Xia's paper [7], the dynamic model of infiltration of liquid metal into preform was derived from fluid mechanics. Later they carried out experiments to study the infiltration process of $\mathrm{CF} / \mathrm{Al}$ composites and determined the infiltration velocity and infiltration coefficient. Wannasin and others [8] used centrifugal infiltration method to measure the critical infiltration load of the solid ceramic particles with different volume fraction of tin lead alloy, and the calculation model for predicting the critical infiltration pressure was established. Rodriguez-Guerrero and others [9] studied the effects of alloy composition and infiltration temperature on the critical pressure and infiltration kinetics during the preparation of aluminum alloy impregnated graphite particles. In Qi's paper [10], the dynamic process of impregnating magnesium alloy with short alumina fiber precast was measured and the forming mechanism of the infiltration front was discussed. However, it is still rare to study the critical infiltration behavior and law of liquid aluminum alloy in the 2D 
carbon fiber preform, and this is very unfavorable for the preparation of $2 \mathrm{D} \mathrm{CF} / \mathrm{Al}$ composite materials.

The common preparation processes of CF/Al composite include gas pressure infiltration method, diffusion bonding method, stirring casting method, vacuum pressure infiltration method, mechanical pressure infiltration method and so on [11-13]. The infiltration and preparation process of $\mathrm{CF} / \mathrm{Al}$ composite by mechanical pressure infiltration method is under the condition of high temperature of the preform and aluminum alloy liquid, and the wettability of carbon fiber and aluminum alloy is better than room temperature. Meanwhile, mechanical pressure infiltration method can provide large infiltration pressure, and this is very helpful to improve the infiltration effect of $\mathrm{CF} / \mathrm{Al}$ composite $[12,13]$. Therefore, mechanical pressure infiltration method has its own advantages to prepare 2D $\mathrm{CF} / \mathrm{Al}$ composites with ideal microstructure and properties, and this method can be used to study the critical infiltration behavior and law of liquid aluminum alloy in the 2D carbon fiber preform.

This article adopted the method of combination of theoretical analysis and experimental study by mechanical pressure infiltration method, and the infiltration law of liquid aluminum alloy in 2D carbon fiber preform were studied. Infiltration law included the mechanical behavior, pressure and time of infiltration alloy and the relationship between them. Moreover, the critical infiltration pressure of liquid aluminum alloy in 2D carbon fiber preform was obtained. This can provide theoretical and experimental basis for the preparation of composite materials with ideal microstructure and properties, and will lay foundation for the application of $\mathrm{CF} / \mathrm{Al}$ composite in industrial fields.

\section{INFILTRATION PRESSURE ANALYSIS AND CALCULATION}

\subsection{Infiltration pressure analysis statically}

When 2D CF/Al composite is prepared by liquid extrusion infiltration, liquid aluminum alloy fills and infiltrates into the gaps of the carbon fiber preform under the effect of high temperature and high pressure. From the statics point of view, carbon fiber preform can be seen as porous medium, when liquid metal infiltrates into the pores of preform. Spontaneous infiltration of liquid metal into preform depends on different pressures caused by capillary action, which can be determined by Young-Kelvin's equation $[14,15]$ that is represented by Eq. 1.

$P_{c}=\frac{2 \gamma_{l v} \cos \theta}{R}$,

where $P_{c}(\mathrm{MPa})$ is the capillary pressure difference; $\gamma_{l v}$ $(\mathrm{N} / \mathrm{m})$ is the surface tension of liquid metal; $\theta\left(^{\circ}\right)$ is the wetting angle between liquid metal and fiber; $R(\mu \mathrm{m})$ is the capillary radius.

When $\theta<\pi / 2$, wetting of liquid metal and fiber is favorable, and infiltration can be spontaneous. When $\theta>\pi / 2$, liquid metal and fiber are not wetted and infiltration cannot be carried out spontaneously, and external pressure should be applied to overcome the capillary pressure and start infiltration $[16,17]$. For a nonwetting system, the minimum external pressure required to start the infiltration process is known as critical infiltration pressure $P_{\text {th }}$ and capillary pressure $P_{c}$ is the most important pressure. The detailed calculation formula of $P_{\text {th }}$ is shown in Eq. 2.

$P_{t h}=P_{v}-\frac{2 \gamma_{l v} \cos \theta}{r}-\rho g h_{0}$,

where $P_{\text {th }}$ is the critical infiltration pressure; $P_{v}$ is the gas pressure in the preform of the fiber infiltration front; $\rho$ is the density of liquid metal; $h$ is the height of liquid metal. $\rho g h_{0}$ and $P_{v}$ are usually very small values which can be neglected. For the infiltration of preform under the condition of air, $P_{v}$ is $0.1 \mathrm{MPa}$. If the infiltration process is under the condition of vacuum, $P_{v}$ is $0 \mathrm{MPa}$.

Three calculation methods with the capillary radius of different kinds of fiber distribution form of preform were discussed in reference [18]. Simplified calculation models of unidirectional uniform distribution carbon fiber, continuous carbon fiber in plane distribution, and short carbon fiber in plane distribution were given. In this study, the carbon fiber cloth is a planar lamination, which is the closest to the approximate calculation model of continuous carbon fiber in plane distribution, so the equivalent radius used to calculate capillary pressure should be calculated according to Eq. 3 [18].

$$
\left\{\begin{array}{l}
a=\left(\pi d_{f} / 4 V_{f}\right) \\
r \approx \frac{1}{2}\left(a-d_{f}\right)=\frac{1}{8 V_{f}}\left(\pi-4 V_{f}\right) d_{f}
\end{array},\right.
$$

where $d_{\mathrm{f}}$ is the fiber diameter, $V_{\mathrm{f}}$ is the. fiber volume fraction, and $a$ is the calculation parameter of fiber distribution. The wetting angle $\theta$ of aluminum alloy and carbon fiber is about $150^{\circ}$, the surface tension $\gamma_{\mathrm{lv}}$ is $0.8 \mathrm{~N} / \mathrm{m}$ [15], and the fiber capillary radius $r$ is $0.38 \mu \mathrm{m}$. Through the calculation Eq. 2, we can get that the critical infiltration pressure of liquid aluminum alloy infiltrated into the carbon fiber preform is about $0.53 \mathrm{MPa}$ when the fiber volume fraction is $45 \%$. The critical infiltration pressure of this form of carbon fiber preform with the fiber volume fraction between $10 \%$ and $50 \%$ is calculated with similar approach, and the values are shown in Fig. 1.

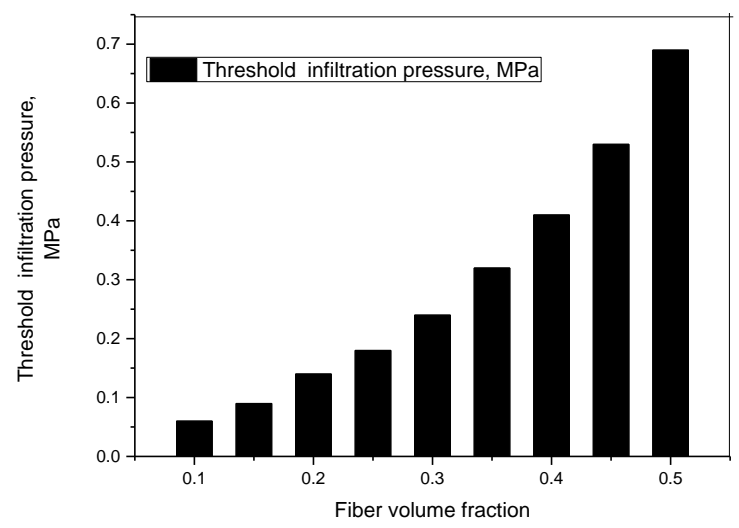

Fig. 1. Critical infiltration pressure of different volume fraction

It shows that critical infiltration pressure increased with the increase of volume fraction of preform. The critical infiltration pressure of liquid aluminum alloy 
infiltrated into the carbon fiber preform reaches $0.69 \mathrm{MPa}$ when the fiber volume fraction is $50 \%$. In order to achieve full and uniform infiltration effect, infiltration pressure should be increased with the increase of fiber volume fraction.

\subsection{Infiltration pressure analysis dynamically}

In the infiltration process of liquid alloy into carbon fiber preform, liquid alloys are mainly affected by capillary pressure, viscous resistance and air resistance. When the thickness of the preform is small, the air resistance is small and capillary pressure and viscous resistance should be considered mainly. Liquid alloy front has capillary force action, and capillary pressure caused by capillary action determines whether the process of infiltration is spontaneous infiltration or under external pressure. Mortensen and others [19] first proposed calculation method of the liquid metal infiltrated into preform from the fluid theory, which ignored the influence on infiltration resistance of fiber cloth distribution form. For the infiltration of preform with uniform fiber distribution, capillary pressure can be calculated by Eq. 4 [19].

$P_{c}=-\frac{4 V_{f} \sigma_{\mathrm{lg}} \cos \theta}{d_{f}\left(1-V_{f}\right)}$,

where $V_{f}$ is the fiber volume fraction, $\sigma_{\lg }$ is the liquid surface tension, $\theta$ is the wetting angle, and $d_{\mathrm{f}}$ is the fiber diameter. Due to the poor wettability of liquid aluminum alloy and carbon fibers $(\theta>\pi / 2)$, the capillary pressure hindered infiltration, so the process of infiltration can only be started after external load is applied. In this study, $V_{f}$ is $45 \%$, diameter $d_{\mathrm{f}}$ is $7 \mu \mathrm{m}$, the surface tension of the aluminum alloy liquid $\left(\sigma_{\mathrm{lg}}\right)$ is $0.8 \mathrm{~N} / \mathrm{m}$ and the wetting angle is $150^{\circ}$. Through the Eq. 4 , the critical infiltration pressure of liquid aluminum alloy infiltrates into $2 \mathrm{D}$ carbon fiber preform is calculated, and it is about 3.24 MPa. When liquid metal flows in laminar flow in the preform, it will be affected by viscous resistance. Pressure drop caused by viscous resistance is calculated by Eq. 5 [19].

$\Delta p=\mu\left(1-V_{f}\right) h^{2} / 2 K t$,

where $\mu$ is the dynamic viscosity, $h$ is the infiltration height, $K$ is the permeability coefficient, and $t$ is the infiltration time. According to the manual, the dynamic viscosity of aluminum alloy is $0.4 \times 10^{-3} \mathrm{~Pa} \cdot \mathrm{s}$ [20], and the infiltration height $h$ is $10 \mathrm{~mm}$. According to our experimental experience in the test, infiltration time is completed within a very short time after extrusion pressure is applied, so $0.2 s$ is taken. The permeability coefficient $K$ can be obtained from the porous pipe model by the BlakeKozeny equation [21], and Eq. 6 is as follows.

$$
K=\frac{d_{f}^{2}\left(1-v_{f}\right)^{3}}{150 v_{f}}
$$

where the carbon fiber diameter $d_{\mathrm{f}}$ is $7 \mu \mathrm{m}$, the volume fraction is $45 \%$. The permeability coefficient $K$ can be obtained and it is $1.2 \times 10^{-11} \mathrm{~m}^{2}$. By substituting this value into Eq. 5 , the pressure drop caused by viscous resistance of the composite is $4.5 \times 10^{3}$ Pa. From Eq. 4 and Eq. 5, Eq. 7 of additional load required to achieve the infiltration of composite materials is obtained as follows [21, 22].

$$
P=-\frac{4 V_{f} \sigma_{\mathrm{lg}} \cos \theta}{d_{f}\left(1-V_{f}\right)}+\frac{\mu\left(1-V_{f}\right) h^{2}}{2 K t} .
$$

The final calculation results of Eq. 4 and Eq. 5 are substituted into Eq. 7, so the additional critical infiltration pressure required to prepare $2 \mathrm{D} \mathrm{CF} / \mathrm{Al}$ composite is 3.24 MPa. In the calculation process of critical infiltration pressure of carbon fiber preform, though dynamic viscosity properties of the filling alloy is considered, some infiltration resistances (such as the gas impurities in fiber resistance, frictional resistance in the process of metal flow, etc.) have been ignored. Meanwhile, fiber distribution of 2D carbon fiber preform is much more complicated than the perforated pipe model, so it is only an idealized calculation model. The calculated value can only give a basic theory reference, and infiltration pressure in practice should be greater than 3.24 MPa. This is just the minimum infiltration pressure of liquid aluminum alloy into the preform, and larger pressure is required to obtain full and uniform infiltration effect of $2 \mathrm{D} \quad \mathrm{CF} / \mathrm{Al}$ composites.

\section{EXPERIMENTAL STUDY ON INFILTRATION LAW}

\subsection{Experimental scheme and process}

\subsubsection{Experimental scheme}

According to the critical infiltration pressure value of liquid aluminum alloy in carbon fiber preform calculated by the previous theory, at least $3.24 \mathrm{MPa}$ pressure is required to achieve the infiltration of liquid aluminum alloy into 2D carbon fiber preform. Experimental research is necessary on the basis of previous theoretical research. The common pressure types of pressure infiltration experiment includes gas pressure infiltration and mechanical pressure infiltration. However, the infiltration scheme under gas pressure is usually complicated and the pressure given by gas pressure is generally limited, which is difficult to obtain full and uniform infiltration effect of carbon fiber preform with large fiber volume fraction. The structure of mechanical pressure infiltration method is simple, and large infiltration pressure can also be provided, so this scheme is used to study the infiltration law of liquid alloy in preform.

In order to obtain the relationship between infiltration time, infiltration depth and infiltration pressure, it is necessary to grasp the infiltration height of liquid alloy into preform under certain mechanical pressure. It is considered to obtain the infiltration height of aluminum alloy liquid in the fiber preform indirectly with the temperature measurement structure of inclined surface, and Fig. 2 is a schematic diagram of the experimental scheme for the study of infiltration law. As can be seen from the figure, the pre-melted aluminum alloy is filled into the carbon fiber preform under the action of mechanical pressure. Different thermocouples are placed in the thermocouple holes. When alloy infiltrates to the corresponding depth of 
the preform, the thermocouple at the height first receives the temperature change. This will provide a feasible scheme for obtaining filling depth of alloy to the preform.

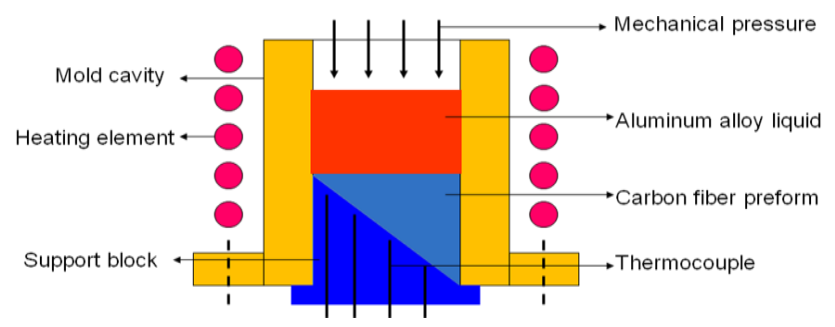

Fig. 2. Schematic diagram of the experimental scheme

\subsubsection{Experimental materials and methods}

The matrix chosen is cast aluminum alloy ZL102 whose chemical composition is shown in Table 1. This alloy has good casting property, and there are no casting hot cracks and holes. Reinforcement is $2 \mathrm{D}$ needled carbon felt whose fiber distribution is also orthogonal fiber lamination, and this is consistent with the reinforcement used in previous theoretical studies. The fiber in preform is T300 carbon fiber whose properties are shown in Table 2.

Table 1. Chemical composition of ZL102 alloy

\begin{tabular}{|c|c|c|c|c|c|c|}
\hline \multicolumn{7}{|c|}{ Content, wt.\% } \\
\hline $\mathrm{Si}$ & $\mathrm{Al}$ & $\mathrm{Fe}$ & $\mathrm{Cu}$ & $\mathrm{Mn}$ & $\mathrm{Zn}$ & $\mathrm{Ti}$ \\
\hline $10.0-13.0$ & Rest & $0.0-0.7$ & $\leq 0.30$ & $\leq 0.5$ & $\leq 0.1$ & $\leq 0.20$ \\
\hline
\end{tabular}

Table 2. Properties of T300 carbon fiber

\begin{tabular}{|c|c|c|c|c|c|}
\hline $\begin{array}{c}\text { Fiber } \\
\text { type }\end{array}$ & $\begin{array}{c}\text { Fiber } \\
\text { monofilament } \\
\text { diameter, } \\
10^{-6} \mathrm{~m}\end{array}$ & $\begin{array}{c}\text { Ultimate } \\
\text { tensile } \\
\text { strength, } \\
\mathrm{MPa}\end{array}$ & $\begin{array}{c}\text { Young's } \\
\text { modulus, } \\
\mathrm{GPa}\end{array}$ & $\begin{array}{c}\text { Elongation, } \\
\%\end{array}$ & $\begin{array}{c}\text { Density, } \\
\mathrm{g} / \mathrm{cm}^{3}\end{array}$ \\
\hline T300 & $6 \sim 8$ & 3500 & 230 & 1.5 & $1.76 \sim 1.80$ \\
\hline
\end{tabular}

\subsubsection{Preparation method of preform}

A preform with carbon fibers in multiple directions in a two-dimensional plane is an important reinforcement, which is two-dimensional (2D) carbon fiber preform. In the pressure infiltration experiment, 2D carbon felt was selected as the preform material. In order to measure the variation of the infiltration depth of aluminum alloy in the preform, the support block was designed as an inclined surface so the preform also needs to be configured into a cylinder with an inclined surface. In addition, the diameter of the preform is slightly larger than that of the infiltration cavity in order to ensure that contact surface of preform and infiltration cavity is tight.

It is necessary to control the shape and size of the preform accurately when cutting and preparing the preform, to ensure the preparation quality of the preform and infiltration experiment smoothly. The prepared 2D carbon fiber preform with inclined surface is shown in Fig. 3.

\subsubsection{Experimental process}

Carbon felt and matrix aluminum alloy were prepared before the experiment, and support block with thermocouple holes was installed. Preform and the aluminum alloy were put into the extrusion and infiltrated cavity, respectively. The thermocouples were installed into the thermocouple holes with different depths.

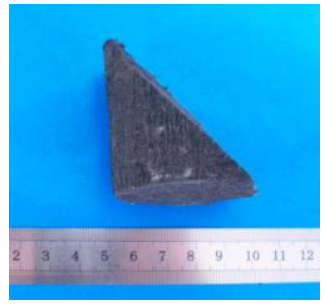

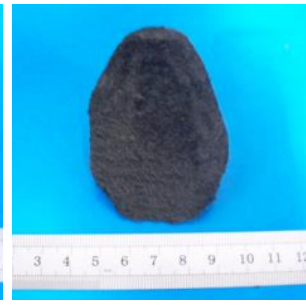

b
Fig. 3. $2 D$ carbon fiber preform for pressure infiltration method: $\mathrm{a}$-view of the side of the preform; $\mathrm{b}$-front view of the preform

The HIOKI8430 data recorder was used to collect test data. Then the alloy was preheated and melted, and the infiltration and extrusion were started when the predetermined temperature was reached. The corresponding experimental parameter values were collected. Several high-precision and k-type armoring thermocouples having an external diameters of $2 \mathrm{~mm}$ were inserted into an axial holes with internal diameters of $3 \mathrm{~mm}$, respectively. The axial hole extended into the supporting slope and was closely connected with the inclined plane. The temperature of the corresponding position of the inclined plane would change when the liquid aluminum alloy reached the preform incline. At the same time, the changing information of the temperature would be collected by the high precision thermocouple on the inclined plane. There was a gradient in the height of the preform of the inclined plane, which could reflect the flow situation of liquid aluminum alloy in the preform.

\subsubsection{Experimental process parameters}

The previous theoretical analysis shows that the critical infiltration pressure is about $3.24 \mathrm{MPa}$ when the liquid aluminum alloy infiltrates in continuous carbon fiber preform, whose fiber volume fraction is $40 \%$. The preheating temperature of the fiber preform should be chosen near the liquidus temperature of the aluminum alloy ZL102, and selected temperature is above $620^{\circ} \mathrm{C}$. Melting temperature of the aluminum alloy chosen is above $660^{\circ} \mathrm{C}$. Based on the analysis above, preheating temperature of preform and alloy melting temperature is $600 \sim 700{ }^{\circ} \mathrm{C}$. The infiltration kinetics analysis shows that prolonged infiltration time can improve the infiltration depth of liquid metal. However, as the time of maintaining pressure is prolonged, the liquid metal solidifies gradually, and the viscosity increases. The filling capacity decreases, and it is effective to improve the infiltration effect. In this paper, pressure holding time is between $1 \mathrm{~min}$ and $5 \mathrm{~min}$. According to the above process parameters and experience of previous experiments, at the same preheated and alloy melting temperatures, $3.5 \mathrm{MPa}$ and $7 \mathrm{MPa}$ are chosen as the infiltration pressures respectively to study the infiltration condition of the aluminum alloy into fiber preform, and holding pressure time is taken as $100 \mathrm{~s}$.

\subsection{Experimental results and discussion}

Fig. 4 shows the CF/Al composite prepared by the mechanical pressure infiltration device. Fig. $4 \mathrm{a}$ is the 
composite prepared under the infiltration pressure of 3.5 $\mathrm{MPa}$, and it can be seen that the fiber preform and aluminum alloy are in separated state, and the infiltration effect of composite is not ideal. Fig. $4 \mathrm{~b}$ is the macroscopic morphology of composite prepared by the infiltration pressure of $7 \mathrm{MPa}$. It can be seen that the fibers are exposed at the bottom of the composite slope and the infiltration effect is poor at point $\mathrm{E}$ of the infiltration depth. Similar studies and analyses were given in reference [13].

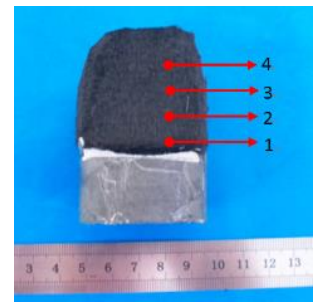

a

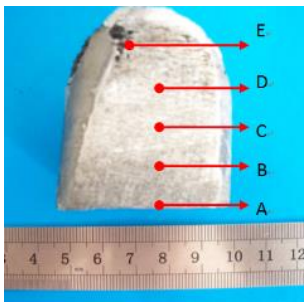

b

Fig. 4. $\mathrm{CF} / \mathrm{Al}$ composites prepared under different pressures: $\mathrm{a}$-pressure of $3.5 \mathrm{MPa}$; $\mathrm{b}$ - pressure of $7 \mathrm{MPa}$

Fig. $5 \mathrm{a}-\mathrm{d}$ illustrates the infiltration effect of composites at different heights, corresponding to the microstructure of A, B, C, and D in Fig. 4 b. Fig. 5 a and Fig. $5 \mathrm{~d}$ show the carbon fibers in the orthogonal direction, and others show the unidirectional carbon fibers.

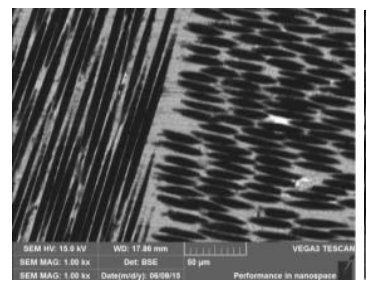

a

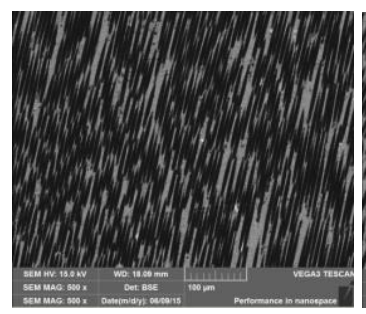

a

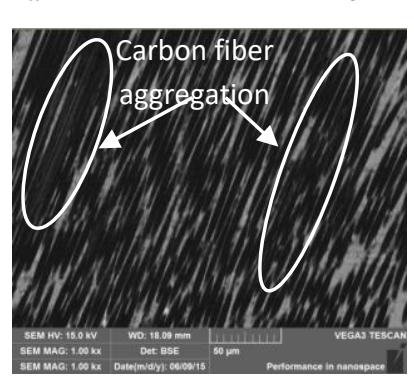

$\mathrm{e}$

b

b
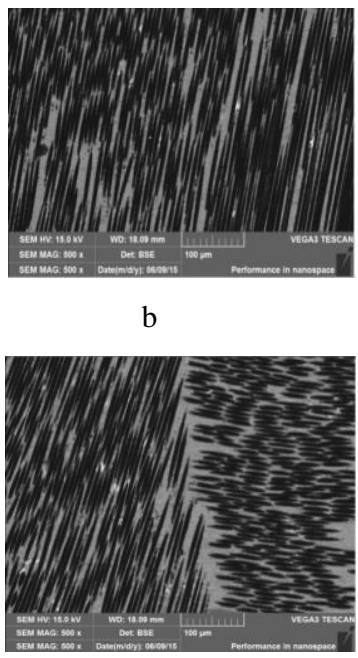

Fig. 5. Microstructure of different height of $\mathrm{CF} / \mathrm{Al}$ composites: $\mathrm{a}$-point $\mathrm{A} ; \mathrm{b}$-point $\mathrm{B} ; \mathrm{c}$-point $\mathrm{C} ; \mathrm{d}$-point $\mathrm{D}$; e-point $\mathrm{E}$

The gray part in the figure is the infiltrated aluminum alloy, and the black part are carbon fibers. It can be seen that a large amount of aluminum alloy has filled into the gaps of the fibers, and the infiltration effect of the sampling position of four different heights are satisfactory. Meanwhile, there are no obvious defects in the microstructure of the four sampling sites, and there are no obvious differences between the infiltration effect, too. But there are also fiber aggregation phenomenon observed at each sampling location. It shows pressure infiltration process experiment device and parameters should be improved so that we can get CF/Al composite with full and uniform infiltration effect. Similar studies were given in reference [24].

Fig. 5 e reflects the infiltration microstructure of the point $\mathrm{E}$ in Fig. 4 b, and it can be seen that the infiltration effect at this height is worse compared with the four positions of A, B, C and D. There is obvious fiber aggregation phenomenon, especially in the area enclosed in the Fig. 5 e. It is obvious that fiber gaps are very small of the adjacent carbon fibers, and the liquid aluminum alloy has not filled into it. The fiber distribution is not uniform, and the infiltration effect is not ideal. The previous theoretical analysis also shows that infiltration process will be affected by capillary resistance, air resistance and viscous resistance. When infiltration front of alloy reaches a larger height, infiltration resistance will increase continuously, until the infiltration pressure can not overcome the resistance, then infiltration is terminated. Infiltration effect of point $\mathrm{E}$ is not ideal, because the infiltration depth is relatively large [21].

Fig. 6 a shows the relationship between temperature and infiltration time of different depth thermocouples when the infiltration pressure is $3.5 \mathrm{MPa}$.

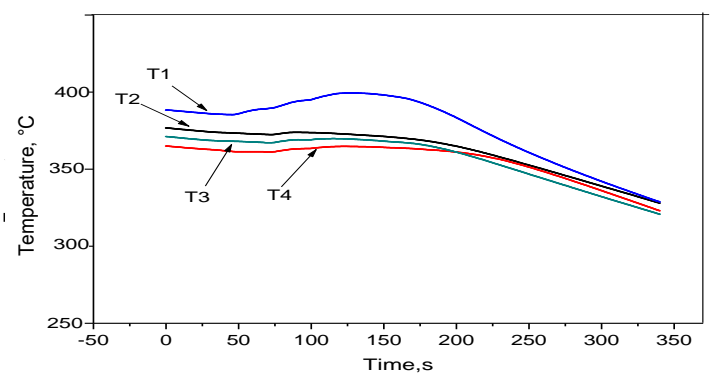

a

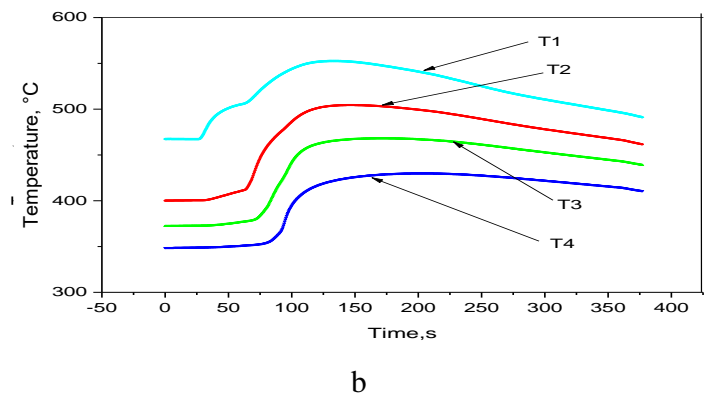

Fig. 6. Relationship between temperature and time: a-pressure of $3.5 \mathrm{MPa}$; $b$ - pressure of $7 \mathrm{MPa}$

In this experiment, there are four effective thermocouples (Corresponding to 1, 2, 3 and 4 points in Fig. 4, respectively). The temperature values obtained by the four thermocouples are expressed in T1, T2, T3 and T4 respectively. When the front alloy liquid infiltration reaches the height of the thermocouple, the temperature of 
the thermocouple will rise sharply. Otherwise, the temperature of the thermocouple will gradually decreased as the experiment progressed. According to the Fig. 6 a, after the infiltration pressure of $3.5 \mathrm{MPa}$ is given, the temperature values collected by the four thermocouples shows a decreasing trend, indicating that the aluminum alloy liquid has not infiltrated into the fiber gaps of the carbon fiber preform [2].

In Fig. 6 a, the temperature of the thermocouple T1 has a short and rising tendency, but it decreases in the end. This illustrates the alloy liquid is filling and heating in the preform gradually, at the combination surface of the carbon fiber preform and the aluminum alloy in the Fig. 4 a. However, the liquid aluminum alloy with high temperature fails to reach the minimum infiltration pressure of the carbon fiber preform, so the surface layer of the carbon fiber preform can not be infiltrated at all, and the infiltration effect is not ideal [10].

Fig. $6 \mathrm{~b}$ is the relationship between temperature and infiltration time of different depth thermocouples when the infiltration pressure is $7 \mathrm{MPa}$. Similar to the above methods, the temperature values of the four different depths (Corresponding to A, B, C and D points in Fig. 4 b) are represented by $\mathrm{T} 1, \mathrm{~T} 2, \mathrm{~T} 3$ and $\mathrm{T} 4$ respectively. It can be seen that temperature values measured by the four thermocouples have risen when the aluminum alloy is given infiltration pressure of $7 \mathrm{MPa}$, and the time of temperature rising is $\mathrm{T} 1>\mathrm{T} 2>\mathrm{T} 3>\mathrm{T} 4$. It is visible that aluminum alloy liquid can begin to fill and infiltrate into the carbon fiber preform smoothly. Since the heights of thermocouples are different, the order of heat received from the aluminum alloy at the infiltration front is different. There are no obvious differences of the temperature rising trend in the four curves, and this corresponds to the better infiltration effect previously.

Although the critical infiltration pressure of the carbon fiber preform calculated by theory is $3.24 \mathrm{MPa}$, a lot of actual infiltration resistances are ignored. It fails to achieve the infiltration of the aluminum alloy liquid into the carbon fiber preform when the infiltration pressure is $3.5 \mathrm{MPa}$. The infiltration can be achieved when the infiltration pressure is $7 \mathrm{MPa}$, and the infiltration depth of the alloy increases continuously, with the increase of the infiltration time. This is consistent with the infiltration law of the alloy liquid in the fiber preform by the previous static and dynamic analysis. This will set up theoretical and experimental basis for the preparation of $2 \mathrm{D} \mathrm{CF} / \mathrm{Al}$ composites with ideal microstructure and properties, and it is beneficial to expand the application scope of this kind of composite materials.

\section{CONCLUSIONS}

1. From the perspective of statics, critical infiltration pressure value of aluminum alloy in two-dimensional layer of carbon fiber preform was analyzed, and following law and conclusions were obtained. With the increase of fiber volume fraction, the pressure increased continuously. When fiber volume fraction was $45 \%$, critical infiltration pressure reached $0.53 \mathrm{MPa}$. Calculation model was quite different from the actual situation of filling process, and it ignores the factors such as viscosity, solidification and air resistance, so it is far from actual experimental value.

2. From the viewpoint of dynamics, theoretical calculated critical infiltration pressure value of liquid aluminum alloy in the 2D carbon fiber preform reaches $3.24 \mathrm{MPa}$. In fact, the infiltration pressure should be greater than $3.24 \mathrm{MPa}$, so that aluminum alloy liquid can begin to infiltrate into the carbon fiber preform. The dynamic calculation process is better than static analysis, but it still ignores the factors such as air resistance and the actual arrangement of fiber, so the calculated value still needs to be improved.

3. Mechanical pressure infiltration scheme was used to research infiltration law. It was found that aluminum alloy liquid could not break through the surface of the carbon fiber preform when the infiltration pressure was $3.5 \mathrm{MPa}$. Carbon fibers and aluminum alloy were separated, and the infiltration was bad. When the infiltration pressure was $7 \mathrm{MPa}$, the infiltration can be achieved, and the infiltration effect gradually decreases with the increase of the infiltration depth, which also verifies the previous theoretical research results. When the infiltration pressure is $7 \mathrm{MPa}$, and the infiltration depth of the alloy increases continuously, with the increase of the infiltration time.This will set up theoretical and experimental basis for preparation and application of $2 \mathrm{D} \mathrm{CF} / \mathrm{Al}$ composites with ideal microstructure and properties.

\section{Acknowledgments}

Author is grateful for financial support from National Natural Science Foundation of China (No. 51705389), Project Supported by Natural Science Basic Research Plan in Shaanxi Province of China (Program No. 2018JQ5013), Project funded by China Postdoctoral Science Foundation (No.2017M613062), Ministry of education production university cooperation education project of China (No. 201902004016), the New experiment and equipment development project of Xidian University (No. SY1954), and the Fundamental Research Funds for the Central Universities and Innovation Fund of Xidian University (No. 5004-20109195867 and 500420109205867).

\section{REFERENCES}

1. Rawal Suraj, P. Interface Structure in Graphite Fiber Reinforced Metal Matrix Composites Surface and Interface Analysis 31 (7) 2001: pp. 692-700. https://doi.org/10.1002/sia.1095

2. Qi, L.H., Su, L.Z., Zhou, J.M., Guan, J.T., Hou, X.H., Li, H.J. Infiltration Characteristics of Liquid AZ91D Alloy into Short Carbon Fiber Perform Journal of Alloys and Compounds 527 2012: pp. $10-15$. https://doi.org/10.1016/j.jallcom.2012.02.133

3. Hufenbach, W., Andrich, M., Langkamp, A., Czulak, A. Fabrication Technology and Material Characterization of Carbon Fibre Reinforced Magnesium Journal of Materials Processing Technology 175 2006: pp. 218-224. https://doi.org/10.1016/j.jmatprotec.2005.04.023 
4. Mortensen, A., Wong, T. Infiltration of Fibrous Preforms by a Pure Metal: Part III. Capillary Phenomena Metallurgical Transactions A 21 (8) 1990: pp. $2257-2263$.

https://doi.org/10.1007\%2FBF02647888

5. Kaptay, G. The Threshold Pressure of Infiltration into Fibrous Preforms Normal to the Fibers' Axes Composites Science and Technology 68 2008: pp. $228-237$. https://doi.org/10.1016/j.compscitech.2007.04.023

6. Yu, S.R., He, Z.M. Theoretical Analysis and Application of Impregnation Pressure of Metal Matrix Short Fiber Composite Materials by Extrusion and Infiltration Acta Materiae Compositae Sinica 2 1995: pp. 15-20 https://doi.org/10.13801/j.cnki.fhclxb.1995.02.004

7. Xia, Z.H., Mao, Z.Y., Zhou, Y.H. Liquid Metal Infiltration Kinetics Model and Its Application Acta Metallurgica Sinica 6 1991: pp. 426-432. http://kns.cnki.net/KCMS/detail.1991

8. Wannasin, J., Flemings, M.C. Fabrication of Metal Matrix Composites by a High-pressure Centrifugal Infiltration Process Journal of Materials Processing Technology 169 2005: pp. $143-149$. https://doi.org/10.1016/j.jmatprotec.2005.03.004

9. Rodriguez-Guerrero, A., Sanchez, S.A., Narciso, J., Louis, E., Rodríguez-Reinoso, F. Pressure Infiltration of Al-12 wt.\% $\mathrm{Si}-\mathrm{X}(\mathrm{X}=\mathrm{Cu}, \mathrm{Ti}, \mathrm{Mg})$ Alloys into Graphite Particle Preforms Acta Materialia 54 (7) 2006: pp. $1821-1831$. https://doi.org/10.1016/j.actamat.2005.11.041

10. Qi, L., Xu, R., Su, L., Zhou, J., Guan, J. Dynamic Measurement on Infiltration Process and Formation Mechanism of Infiltration Front Transactions of Nonferrous Metals Society of China 20 2010: pp. $980-986$. https://doi.org/10.1016/s1003-6326(09)60245-4

11. Daoud, A. Microstructure and Tensile Properties of 2014Al Alloy Reinforced with Continuous Carbon Fibers Manufactured by Gas Pressure Infiltration Materials Science and Engineering A 391 2005: pp. 114-120. https://doi.org/10.1016/j.msea.2004.08.075

12. Zhang, Y.H., Wu, G.H. Microstructure and Mechanical Properties of 2D-Gr/Al Composite Transactions of Nonferrous Metals Society of China 20 2010: pp. $2148-2151$. https://d.old.wanfangdata.com.cn/Periodical/zgysjsxbe2006z3064
13. Ma, Y.Q., Qi, L.H., Zhang, T., Zhou, J.M., Yao, G.Z. Study on Defects of $2 \mathrm{D}-\mathrm{C}_{\mathrm{f}} / \mathrm{Al}$ Composite Prepared by Liquid-solid Extrusion Following Vacuum Infiltration Technique International Journal of Aadvanced Manufacturing Technology 88 2017: pp. 89-96. https://doi.org/10.1007/s00170-016-8768-0

14. Uozumi, H., $\quad$ Kobayashi, K., $\quad$ Nakanishi, K., Matsunaga, T., $\quad$ Shinozaki, K., $\quad$ Sakamoto, H., Tsukada, T., Masuda, C., Yoshida, M. Fabrication Process of Carbon Nanotube/light metal matrix composites by Squeeze Casting Materials Science \& Engineering A 495 2008: pp. $282-287$. https://doi.org/10.1016/j.msea.2007.11.088

15. Hu, L., Luo, S., Huo, W. Determination of Threshold Pressure for Infiltration of Liquid Aluminium into Short Alumina Fiber Preform Transactions of Nonferrous Metals Society of China 4 1996: pp. 133-137. https://www.researchgate.net/publication/289359066

16. Andrews, R.M., Mortensen, A. Lorentz Force Infiltration of Fibrous Preforms Metallurgical Transactions A 12 1991: pp. $2903-2915$. https://doi.org/10.1007/BF02650251

17. Li, W., Liu, L., Shen, B. The Fabrication and Properties of Short Carbon Fiber Reinforced Copper Matrix Composites Journal of Composite Materials 24 2011: pp. 2567-2571. https://doi.org/10.1177/0021998311401108

18. Zhang, G., Zhao, C. Metal Matrix Composites. Shanghai, Shanghai Jiao Tong University press, 1995: pp. 51-52.

19. Mortensen, A., Cornie, J.A. On the Infiltration of Metal Matrix Composites Metallurgical Transactions A 13 1987: pp. $1160-1164$. https://doi.org/10.1007/BF02668570

20. Li, C., Liu, H., He, W., Hao, Z., Zhao, T., Zhang, L. Viscosity and Effect Factors of Aluminium Alloy Melt Light Alloy Fabrication Technology 10 2005: pp. 22-25. http://en.cnki.com.cn/Article_en/CJFDTOTALQHJJ200510006.htm

21. Guan, J., Qi, L., Liu, J., Zhou, J., Wei, X. Threshold Pressure and Infiltration Behavior of Liquid Metal into Fibrous Preform Transactions of Nonferrous Metals Society of China 23 2013: pp. 3173-3179. https://doi.org/10.1016/S1003-6326(13)62849-6

22. Hu, L., Yang, Y., Luo, S., Xu, X. Investigation on the Kinetics of Infltration of Liquid Aluminium into an Alumina Fbrous Preform Journal of Materials Processing Technology 94 1999: pp. 227-230. https://doi.org/10.1016/s0924-0136(99)00099-0 